\title{
A geochemical investigation of the free and carbonate-bound organic matter in the clay-sized fraction of argillaceous source rocks and its significance for biogenic interpretation
}

\author{
Yue Zhao ${ }^{1,2} \cdot$ Jin-Gong Cai ${ }^{2} \cdot$ Tian-Zhu Lei ${ }^{3} \cdot$ Yan Yang ${ }^{3,4}$
}

Received: 13 December 2017 / Published online: 22 October 2018

(c) The Author(s) 2018

\begin{abstract}
The molecular composition and biomarker distribution of various occurrences of organic matter in argillaceous source rocks developed in fresh and saline lacustrine environments were revealed by successive treatments of solvent extraction followed by acid hydrolysis using gas chromatography-mass spectrometry. The free fraction obtained by solvent extraction provided abundant geochemical information concerning the sedimentary environment, thermal maturity and biogenic origin, and obvious differences existed between fresh and saline lacustrine source rock samples. Our research results indicate that the carbonate-mineral-bound (CM-bound) fraction released by successive acid hydrolysis could also serve as a significant biogenic indicator, as the bicyclic sesquiterpenoids, indicative of Botryococcus braunii origin, were specifically detected in quite high abundance in the acid-soluble fraction. In addition, the light end hydrocarbons were much better preserved in the acid-soluble fraction, and elemental sulfur was only detected in the CM-bound fraction, suggesting a relatively confined environment for the CM-bound fraction, which thus could preserve additional geochemical information compared to that of the free fraction. The CM-bound fraction also exhibited discernable differences between fresh and saline lacustrine samples. Therefore, it can be concluded that comprehensive analysis of free and CM-bound fractions in the argillaceous source rocks can provide a more authentic and objective interpretation of geologic conditions.
\end{abstract}

Keywords Argillaceous source rock - Occurrence - Free fraction - CM-bound fraction - Bicyclic sesquiterpenoids . Botryococcus braunii · Biogenic significance

\section{Introduction}

Analysis of organic matter (OM) on the molecular level has proven to be an effective method to identify possible biogenic origin of hydrocarbon source rocks (Volkman 1988;

Edited by Jie Hao

Jin-Gong Cai

jgcai@tongji.edu.cn

1 Research Institute of Petroleum Exploration and Development, Beijing 100083, China

2 State Key Laboratory of Marine Geology, Tongji University, Shanghai 200092, China

3 Key Laboratory of Petroleum Resources Research, Institute of Geology and Geophysics, Chinese Academy of Sciences, Lanzhou 730000, Gansu, China

4 Jidong Oil Company, PetroChina, Tangshan 063004, Hebei, China
Grantham et al. 1988; Peters et al. 2005; Huang et al. 2016). In conventional geochemical studies, the free fraction of OM is generally obtained by solvent extraction, and then analyzed using gas chromatography-mass spectrometry (GC/MS) to provide its molecular composition. Based on $n$-alkane and biomarker distribution characteristics, OM sources could be inferred. Furthermore, the potential of source rocks could be assessed, and the phases of hydrocarbon products could be predicted, which is of significant importance in guiding petroleum exploration and development. Thus, source rock biogenic interpretation is fundamentally important in geochemical studies. However, this concept has been reappraised upon the recognition of other occurrences of OM in source rocks, including claymineral interlayer-absorbed, clay-mineral surface-absorbed, carbonate-crystal wrapped, asphaltene-occluded, and asphaltene/kerogen covalently bonded OM fractions (e.g. Guan et al. 1998; Xie et al. 2000; Wang and Cheng 2000; Farrimond et al. 2003; Cai et al. 2013; Li et al. 2014; 
Snowdon et al. 2016; Chen and Peng 2017), which have previously been overlooked in conventional geochemical studies. In addition to the free fraction of $\mathrm{OM}$ in source rocks, the remaining bound fraction could also preserve significant geochemical information concerning OM origin and maturity (Farrimond et al. 2003; Ma et al. 2008; Li et al. 2014; Wu and Geng 2016). Because of the steric protection of inorganic minerals and kerogen/asphaltene macromolecular networks, the thermal evolution of bound OM shows retarded responses to ambient environmental changes when subjected to increased pressure and temperature during gradual burial, thus possessing the capability to better preserve the primitive features of $\mathrm{OM}$ compared to the free fraction. This is of great significance for geochemical studies of highly matured or severely biodegraded samples (Ma et al. 2008; Chen et al. 2011; Li et al. 2014; Wu and Geng 2016; Glombitza et al. 2016). Various experimental procedures have been established to release the bound OM, which makes further geochemical characterization possible. Generally, the mineral-bound OM could be released via chemical treatments, such as saponification and acid hydrolysis, after solvent extraction, which first removes the free OM (Zegouagh et al. 2000; Warren and Ziegler 2017); the kerogen/asphaltene-bound OM could be released via oxidative or thermal degradation of kerogen/asphaltene, such as ruthenium-ion-catalyzed oxidation and pyrolysis GC/MS (Li et al. 2004; Pan et al. 2017). Based on previous studies of bound OM, it is generally accepted that the bound fraction is of relatively lower maturity and better authenticity compared to the free fraction (French et al. 2015; Glombitza et al. 2016; Wu and Geng 2016).

The Dongying Sag in the Bohai Bay Basin is a petroleum-rich unit in North China, which has preserved abundant lacustrine fine-grained deposits of great thickness, among which the lower member $3\left(\mathrm{Es}^{3}\right)$ and upper member $4\left(\mathrm{Es}^{4}\right)$ of the Shahejie Formation are the two primary sets of source rocks contributing the most petroleum production (Pang et al. 2005; Li et al. 2008a, b; Zhang et al. 2009; Guo et al. 2011; Zhu and Jin 2015; Li et al. 2017a; Ma et al. 2017a). Both $\mathrm{Es}^{3}$ and $\mathrm{Es}^{4}$ were deposited under anoxic bottom-water conditions with persistent lake water stratification, and exhibit clear climatically driven rhythmicity and lamination (Zhang et al. 2009). However, the depositional environment of $\mathrm{Es}^{3}$ and $\mathrm{Es}^{4}$ is markedly distinctive, as the $\mathrm{Es}^{3}$ and $\mathrm{Es}^{4}$ were deposited in fresh and saline lacustrine environments respectively (Zhang et al. 2009), thus providing an opportunity to explore the geochemical features of various OM occurrences with similar sediment input yet under different depositional conditions. The carbonate minerals (CMs) serve as a significant mineralogical component of the Shahejie Formation (Guo et al. 2014; Ma et al. 2016; Li et al. 2017a), thus may contain a certain amount of OM encased in crystals, which deserves further geochemical characterization for its potential value of biogenic indication. Hence, both the free fraction and the $\mathrm{CM}$-bound fraction of $\mathrm{Es}^{3}$ and $\mathrm{Es}^{4}$ source rocks were subjected to sequential treatments to determine whether the CM-bound fraction could provide additional geochemical information on $\mathrm{OM}$ origin and maturity.

In this study, the $<2 \mu \mathrm{m}$ clay-sized fractions of $\mathrm{Es}^{3}$ and $\mathrm{Es}^{4}$ argillaceous source rock samples were subjected to sequential treatments of solvent extraction followed by acid hydrolysis to determine the geochemical characteristics of both the free and CM-bound fraction. Complementary analysis using Rock-Eval, X-ray diffraction (XRD), and GC/MS of the saturated hydrocarbons provided detailed insight into the molecular composition and biomarker distribution of the free and CM-bound fractions.

\section{Experimental}

\subsection{Materials}

The $\mathrm{Es}^{3}$ and $\mathrm{Es}^{4}$ source rock samples were core samples collected from the Dongying Sag, Bohai Bay Basin, North China. The depth range of the $\mathrm{Es}^{3}$ and $\mathrm{Es}^{4}$ source rock samples was from 3204.0 to $3452.2 \mathrm{~m}$, and they were dominated by type I kerogen. Source rock samples were pulverized to pass through a 100-mesh sieve followed by desiccation in a vacuum at $40{ }^{\circ} \mathrm{C}$ for $48 \mathrm{~h}$ before use. Dichloromethane (DCM), $n$-pentane, methanol $(\mathrm{MeOH})$, and hydrochloric acid $(\mathrm{HCl})$ used in the experiments were analytical grade reagents, and all the organic solvents were distilled prior to usage.

\subsection{Separation of the $<2 \mu \mathrm{m}$ clay-sized fraction of argillaceous source rocks}

A certain amount of $\mathrm{Es}^{3}$ and $\mathrm{Es}^{4}$ source rock samples were ground into fine powders, then immersed in deionized water in 3000-ml beakers. The fine powders were fully dispersed via repeated quick stirring and ultrasonic oscillation, and as a result, the $<2 \mu \mathrm{m}$ clay-sized fractions were suspended in the water solution. According to the Stokes Rule, at room temperature, after $8 \mathrm{~h}$ discrete settling, the water portion of $10 \mathrm{~cm}$ or less below the surface was specifically left with the $<2 \mu$ m clay-sized fraction, which was then separated via siphoning and further centrifugation. This process was repeated several times to obtain a sufficient amount of clay-sized fractions (CFs), approximately $30 \mathrm{~g}$ in total. The $\mathrm{CFs}$ were oven-dried at $40{ }^{\circ} \mathrm{C}$ and stored in a refrigerator for further analysis. All subsequent experimental procedures and analyses were carried out on the $<2 \mu \mathrm{m} \mathrm{CFs}$, as the $\mathrm{OM}$ and clay minerals were 
relatively enriched in this size range, partly because of the organic-inorganic interactions between them (Kennedy et al. 2002; Cai et al. 2013).

\subsection{Rock-Eval pyrolysis}

Rock-Eval pyrolysis was performed using the Rock-Eval 6 instrument, manufactured by Vinci Technologies, to obtain the fundamental geochemical characteristics of the $\mathrm{Es}^{3}$ and $\mathrm{Es}^{4}$ CFs following the Basic Method as described by Lafargue et al. (1998) and Behar et al. (2001). Rock-Eval 6 is equipped with a flame ionization detector (FID) to monitor the amount of hydrocarbons, and two infrared (IR) cells for monitoring the amount of $\mathrm{CO}$ and $\mathrm{CO}_{2}$ from pyrolysis and oxidation, respectively. The CFs were initially heated at $300{ }^{\circ} \mathrm{C}$ for $3 \mathrm{~min}$ to generate a Rock-Eval $\mathrm{S}_{1}$ peak, representing the residual volatile and semi-volatile hydrocarbons. Then the samples were heated from 300 to $600{ }^{\circ} \mathrm{C}$ at a rate of $25^{\circ} \mathrm{C} / \mathrm{min}$, yielding the $\mathrm{S}_{2}$ peak as a result of the thermal degradation products of insoluble OM, mainly kerogen. The temperature at the maximum of the $S_{2}$ peak was converted to the $T_{\max }$ parameter, which can be used to indicate thermal maturity. The $\mathrm{S}_{3}$ curve corresponds to the amount of $\mathrm{CO}_{2}$ generated from OM during the initial isothermal heating stage and the programmed heating phase up to $400{ }^{\circ} \mathrm{C}$. The $\mathrm{CO}_{2}$ generated between 400 and $650{ }^{\circ} \mathrm{C}$ was a result of the thermal decomposition of the carbonates. Other Rock-Eval parameters such as hydrogen index (HI) and oxygen index (OI) could also be obtained.

\subsection{XRD analysis}

In this study, XRD analysis was employed to determine the mineralogical composition of the $\mathrm{Es}^{3}$ and $\mathrm{Es}^{4} \mathrm{CFs}$ using a powder X-ray diffractometer (PANalytical XPERT-PRO MPD), operated at $30 \mathrm{kV}$ and $40 \mathrm{~mA}$, with a scanning rate of $2^{\circ}(2 \theta) / \mathrm{min}$. The CFs were air-dried and then backpressed into an aluminum holder to produce a randomly oriented specimen. Equal amounts of $\mathrm{Al}_{2} \mathrm{O}_{3}$ crystal powder were added as an internal standard to obtain a semi-quantitative percentage of certain minerals in the CFs, with an accuracy of $\pm 5 \%$. Identification of minerals was conducted using EVA (Bruker AXS Inc.) software by comparing them to reference mineral patterns archived in the Powder Diffraction Files of the International Center for Diffraction Data and other available databases.

\subsection{Sequential treatments}

As Fig. 1 shows, $30 \mathrm{~g}$ of CFs were extracted with dichloromethane (DCM) to obtain the free organic fraction. The DCM extraction was evaporated to dryness and precisely weighed. The extracts were initially dissolved in $n$-pentane to remove asphaltene, then the maltene fraction was separated into saturated hydrocarbons (SHs), aromatic hydrocarbons (AHs), and nonhydrocarbons (NHs) via alumina/silica gel-column chromatography using $n$-pentane, DCM, and $\mathrm{MeOH}$, respectively. Each fraction was evaporated to dryness and precisely weighed, and the $\mathrm{SH}$ fraction was further analyzed using GC/MS.

The extracted residue (Residue 1) was then subjected to acid hydrolysis using $6 \mathrm{M} \mathrm{HCl}$, and a certain amount of $\mathrm{MeOH}$ was added to the reaction mixture. The reaction system was magnetically stirred for $12 \mathrm{~h}$ at $60{ }^{\circ} \mathrm{C}$. The acid hydrolysis residue (Residue 2) and reaction liquid (RL) were separated by filtration. Residue 2 was repeatedly washed using de-ionized water until the $\mathrm{pH}$ was neutral. Then, the neutral residue was extracted by DCM to afford organic phase (OP) 1. Both the RL and de-ionized-waterwashed solution were repeatedly extracted using DCM to afford OP 2 and OP 3. OP 1, OP 2, and OP 3 were incorporated, then evaporated to dryness to obtain the CMbound fraction, which was precisely weighed and divided into $\mathrm{SH}, \mathrm{AH}, \mathrm{NH}$, and asphaltene using the same treatment method as that of the free fraction previously described. Each fraction was precisely weighed and the $\mathrm{SH}$ fraction was further analyzed using GC/MS.

\subsection{GC/MS analysis}

GC/MS analysis of the $\mathrm{SH}$ fraction was performed using an HP-6890 N gas chromatograph (Agilent, USA; injector temperature $280{ }^{\circ} \mathrm{C}$ ) interfaced to an $\mathrm{HP}-5973 \mathrm{~N}$ mass spectrometer (Agilent, USA; electron energy $70 \mathrm{eV}$, source temperature $230{ }^{\circ} \mathrm{C}$, quadrupole temperature $150{ }^{\circ} \mathrm{C}$ ). Gas chromatography was carried out on an HP-5 fused silica column $(30 \mathrm{~m} \times 0.25 \mathrm{~mm} \times 0.25 \mathrm{~mm}, \quad 0.25-\mu \mathrm{m}$ film thickness). The $\mathrm{GC}$ oven was programmed from $40{ }^{\circ} \mathrm{C}$ (held for $2 \mathrm{~min}$ ) to $100{ }^{\circ} \mathrm{C}$ at $3{ }^{\circ} \mathrm{C} / \mathrm{min}$ and further heated to $290{ }^{\circ} \mathrm{C}$ at $4{ }^{\circ} \mathrm{C} / \mathrm{min}$ with a final hold time of $30 \mathrm{~min}$. Ultra-high purity helium was used as carrier gas with a constant flow of $1.2 \mathrm{ml} / \mathrm{min}$. Mass spectra were acquired in full scan mode. All hydrocarbon compounds were confirmed using GC/MS fragment ion comparisons to the National Institute of Standards and Technology (NIST) library and previous published literature.

\section{Results}

\subsection{Rock-Eval pyrolysis of the Es ${ }^{3}$ and Es ${ }^{4}$ CFs}

Rock-Eval pyrolysis of $\mathrm{Es}^{3} \mathrm{CFs}$ indicated that total organic carbon (TOC) varied from $4.33 \%$ to $11.47 \%$, whereas $\mathrm{Es}^{4}$ ranging from $3.05 \%$ to $4.93 \%$ (Table 1). Pyrolysis $S_{1}, S_{2}$, 


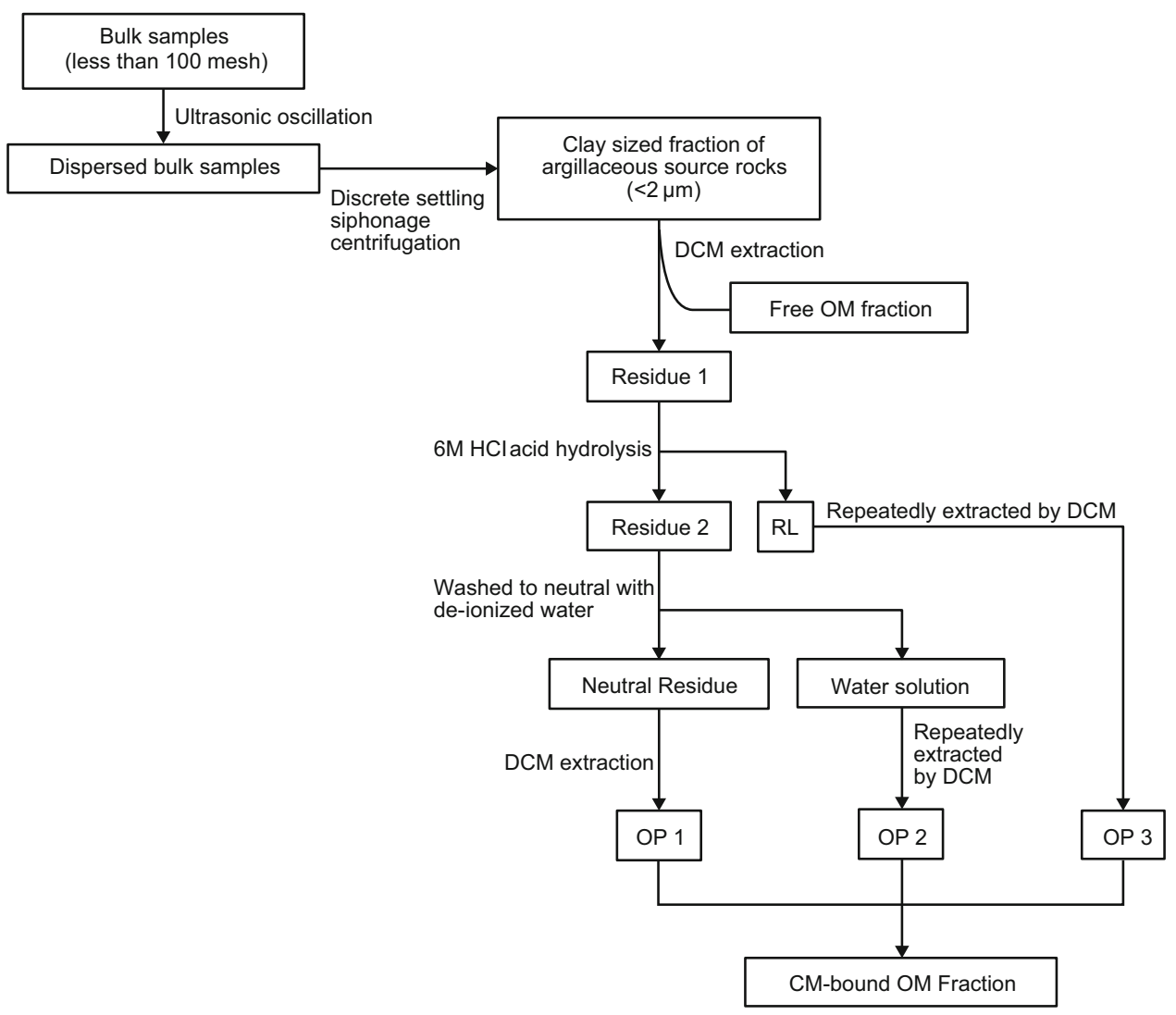

Fig. 1 Procedure for sequential treatments of CFs

Table 1 The fundamental geochemical characteristics of clay-sized fractions of $\mathrm{Es}^{3}$ and $\mathrm{Es}^{4}$ argillaceous source rocks from Rock-Eval pyrolysis

\begin{tabular}{|c|c|c|c|c|c|c|c|c|c|c|c|c|c|c|c|c|}
\hline $\begin{array}{l}\text { Sample } \\
\text { number }\end{array}$ & $\begin{array}{l}\text { Geologic } \\
\text { age }\end{array}$ & $\begin{array}{l}\text { Depth, } \\
\text { m }\end{array}$ & $\begin{array}{l}S_{1}, \\
\mathrm{mg} / \\
\mathrm{g}\end{array}$ & $\begin{array}{l}S_{2}, \\
\mathrm{mg} / \mathrm{g}\end{array}$ & PI & $\begin{array}{l}T_{\max }, \\
{ }^{\circ} \mathrm{C}\end{array}$ & $\begin{array}{l}\mathrm{S}_{3} \mathrm{CO}, \\
\mathrm{mg} / \mathrm{g}\end{array}$ & $\begin{array}{l}\mathrm{S}_{3}{ }^{\prime} \mathrm{CO}, \\
\mathrm{mg} / \mathrm{g}\end{array}$ & $\begin{array}{l}\mathrm{S}_{3}, \\
\mathrm{mg} / \mathrm{g}\end{array}$ & $\begin{array}{l}\mathrm{PC}, \\
\%\end{array}$ & $\begin{array}{l}\mathrm{RC}, \\
\%\end{array}$ & $\begin{array}{l}\text { TOC, } \\
\%\end{array}$ & HI & OICO & OI & $\begin{array}{l}\text { MinC, } \\
\%\end{array}$ \\
\hline 1327 & $\mathrm{Es}^{3}$ & 3204.0 & 6.16 & 86.35 & 0.07 & 440 & 0.60 & 1.20 & 1.04 & 7.76 & 3.71 & 11.47 & 753 & 5 & 9 & 2.36 \\
\hline 1301 & $\mathrm{Es}^{3}$ & 3300.9 & 2.95 & 35.04 & 0.08 & 441 & 0.22 & 1.00 & 0.64 & 3.20 & 2.53 & 5.73 & 612 & 4 & 11 & 2.97 \\
\hline 1302 & $\mathrm{Es}^{3}$ & 3315.1 & 3.57 & 23.53 & 0.13 & 439 & 0.12 & 0.40 & 0.63 & 2.28 & 2.05 & 4.33 & 543 & 3 & 15 & 1.42 \\
\hline 1303 & $\mathrm{Es}^{4}$ & 3326.8 & 3.32 & 16.98 & 0.16 & 434 & 0.16 & 0.60 & 0.78 & 1.73 & 1.82 & 3.55 & 478 & 5 & 22 & 3.53 \\
\hline 1306 & $\mathrm{Es}^{4}$ & 3369.9 & 3.36 & 12.96 & 0.21 & 432 & 0.08 & 0.60 & 0.80 & 1.39 & 1.66 & 3.05 & 425 & 3 & 26 & 2.25 \\
\hline 1312 & $\mathrm{Es}^{4}$ & 3452.2 & 8.12 & 22.58 & 0.26 & 432 & 0.11 & 0.60 & 0.94 & 2.59 & 2.34 & 4.93 & 458 & 2 & 19 & 3.75 \\
\hline
\end{tabular}

and $S_{3}$ of the $\mathrm{Es}^{3} \mathrm{CFs}$ varied between $2.95-6.16 \mathrm{mg} \mathrm{HC} / \mathrm{g}$ sample, 23.53-86.35 mg HC/g sample, and 0.63-1.04 mg $\mathrm{CO}_{2} / \mathrm{g}$ sample, respectively, whereas pyrolysis $S_{1}, S_{2}$, and $\mathrm{S}_{3}$ of $\mathrm{Es}^{4}$ the CFs varied between $3.32-8.12 \mathrm{mg} \mathrm{HC} / \mathrm{g}$ sample, 12.96-22.58 mg HC/g sample, and 0.78-0.94 mg $\mathrm{CO}_{2} / \mathrm{g}$ sample, respectively (Table 1 ). The TOC, $S_{1}$, and $S_{2}$ parameters suggested that both the $\mathrm{Es}^{3}$ and $\mathrm{Es}^{4} \mathrm{CFs}$ were of relatively high OM content; however, distinct heterogeneity existed along the source rock developed profile, which could be ascribed to climate changes and lacustrine basin evolution (Zhang et al. 2009). HI and OI were generally utilized to define the OM type. In this case, both the $\mathrm{Es}^{3}$ and $\mathrm{Es}^{4} \mathrm{CFs}$ featured high $\mathrm{HI}$ values and low OI values (Table 1), suggesting that the dominating OM is type I kerogen, mainly derived from algal material. In addition, the relatively high pyrolysis $S_{2}$ values suggested that both the $\mathrm{Es}^{3}$ and $\mathrm{Es}^{4} \mathrm{CFs}$ had not achieved their full hydrocarbon generation potential. The $\mathrm{Es}^{3} \mathrm{CFs}$ were of relatively higher pyrolysis $S_{2}$ and lower pyrolysis $S_{1}$ values compared to $\mathrm{Es}^{4}$, suggesting better hydrocarbon expulsion of the Es ${ }^{4}$ source rocks, which has been demonstrated in practice (Zhang et al. 2009). 


\subsection{XRD analysis of the $\mathrm{Es}^{3}$ and $\mathrm{Es}^{4} \mathrm{CFs}$}

XRD analysis of the $\mathrm{Es}^{3}$ and $\mathrm{Es}^{4} \mathrm{CFs}$ provided the mineralogical composition of both the bulk samples and clay minerals (Table 2). Both the $\mathrm{Es}^{3}$ and $\mathrm{Es}^{4}$ samples are dominated by clay minerals, quartz, and calcite, which altogether occupy $83 \%-100 \%$ of the total (Table 2). Furthermore, the clay minerals and calcite had close relationships with OM preservation, mainly because the outer and interlayer surface of clay minerals could absorb OM (Kennedy et al. 2002; Cai et al. 2013), and the carbonate crystals could entrap OM during early diagenesis (Xie et al. 2000; Wang and Cheng 2000; Li et al. 2008a, b). The $\mathrm{Es}^{3} \mathrm{CFs}$ are composed of $55 \%-71 \%$ clay minerals and $7 \%-24 \%$ carbonate minerals, whereas the $\mathrm{Es}^{4} \mathrm{CFs}$ are composed of $37 \%-57 \%$ clay minerals and $22 \%-37 \%$ carbonate minerals (Table 2). However, the clay mineral composition exhibits distinct differences between $\mathrm{Es}^{3}$ and $\mathrm{Es}^{4}$, mainly reflected in the illite and smectite interlayer ratios, with $\mathrm{Es}^{4} \mathrm{CFs}$ of much higher illite compositional percentage, reaching $100 \%$ at most. The saline lacustrine environment of $\mathrm{Es}^{4}$ source rocks was a major cause for its acceleration of smectite illitization, which resulted in desorption and discharge of smectite interlayer absorbed $\mathrm{OM}$, and made $\mathrm{Es}^{4}$ a more significant contributor to hydrocarbon production than $\mathrm{Es}^{3}$ ( $\mathrm{Li}$ et al. 2017b). It must be noted that the XRD result is semi-quantitative, with an accuracy of $\pm 5 \%$ due to the limit of instrument; thus, it should be borne in mind that the "-" symbol in Table 2 does not mean the absence of a certain mineral. In fact, the mineralogical composition of these CFs is actually an artifact due to the physical separation of the $<2-\mu \mathrm{m}$ fraction. The large amount of clay minerals help to enrich $\mathrm{OM}$ in the clay-sized range (Kennedy et al. 2002; Cai et al. 2013; Zhu et al. 2016), and the relatively high amount of carbonates ensures the reliability of CM-bound $\mathrm{OM}$ analysis.

\subsection{Sequential treatments of the $\mathrm{Es}^{3}$ and $\mathrm{Es}^{4} \mathrm{CFs}$}

\subsubsection{Abundance and group composition of the free and $\mathrm{CM}$-bound fractions}

The abundances of the free and CM-bound fractions show great differences, as the amounts of free fraction of both the $\mathrm{Es}^{3}$ and $\mathrm{Es}^{4} \mathrm{CFs}$ are much larger than those of the CMbound fraction (Table 3). The total amount of $\mathrm{Es}^{3}$ free fractions are within the range of $8.61-13.10 \mathrm{mg} / \mathrm{g} \mathrm{CF}$, whereas the CM-bound fractions are within the range of $0.17-0.22 \mathrm{mg} / \mathrm{g}$ CF. The total amount of $\mathrm{Es}^{4}$ free fractions are in the range of $8.74-17.86 \mathrm{mg} / \mathrm{g} \mathrm{CF}$; in contrast, the CM-bound fractions are only $0.15-0.28 \mathrm{mg} / \mathrm{g} \quad \mathrm{CF}$

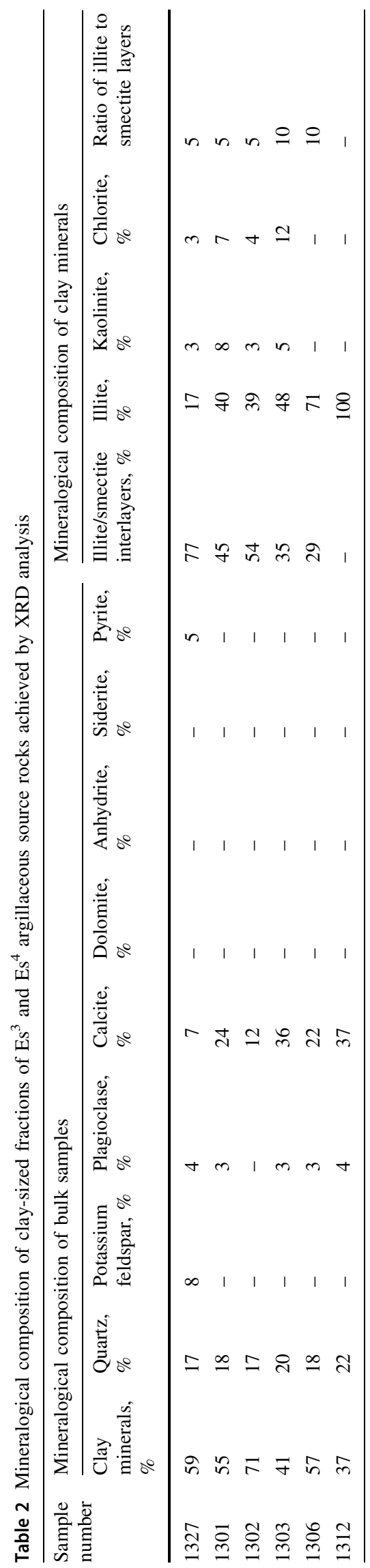


Table 3 Quantitative measurements of the free and CM-bound fraction of the clay-sized fractions of $\mathrm{Es}^{3}$ and $\mathrm{Es}^{4}$ argillaceous source rocks

\begin{tabular}{|c|c|c|c|c|c|c|c|c|c|c|c|c|c|c|}
\hline \multirow[t]{2}{*}{ Sample number } & \multicolumn{7}{|c|}{ The free fraction } & \multicolumn{7}{|c|}{ The CM-bound fraction } \\
\hline & Total & SH & $\mathrm{AH}$ & $\mathrm{NH}$ & Asphal & $\mathrm{TH}$ & S/A & Total & $\mathrm{SH}$ & $\mathrm{AH}$ & $\mathrm{NH}$ & Asphal & $\mathrm{TH}$ & S/A \\
\hline 1327 & 13.10 & 8.60 & 1.32 & 2.77 & 0.41 & 9.92 & 6.52 & 0.21 & 0.01 & 0.03 & 0.13 & 0.04 & 0.04 & 0.42 \\
\hline 1301 & 8.61 & 5.15 & 1.43 & 1.78 & 0.25 & 6.58 & 3.60 & 0.22 & 0.04 & 0.03 & 0.07 & 0.08 & 0.07 & 2.28 \\
\hline 1302 & 11.79 & 7.91 & 1.34 & 2.14 & 0.40 & 9.25 & 5.90 & 0.17 & 0.05 & 0.01 & 0.08 & 0.03 & 0.06 & 4.50 \\
\hline 1303 & 8.74 & 4.01 & 2.31 & 2.34 & 0.08 & 6.32 & 1.74 & 0.15 & 0.03 & 0.01 & 0.06 & 0.05 & 0.04 & 2.73 \\
\hline 1306 & 9.78 & 6.93 & 1.01 & 1.68 & 0.16 & 7.94 & 6.86 & 0.20 & 0.04 & 0.02 & 0.08 & 0.06 & 0.06 & 2.25 \\
\hline 1312 & 17.86 & 13.35 & 2.84 & 1.46 & 0.21 & 16.19 & 4.70 & 0.28 & 0.08 & 0.02 & 0.09 & 0.09 & 0.10 & 4.50 \\
\hline
\end{tabular}

Total the total amount of each fraction $=\mathrm{SH}+\mathrm{AH}+\mathrm{NH}+$ Asphal; $\mathrm{SH}$ Saturated Hydrocarbons; $A H$ aromatic hydrocarbons; $\mathrm{NH}$ nonhydrocarbon; Asphal asphaltene; $T H$ total hydrocarbons $=\mathrm{SH}+\mathrm{AH} ; \mathrm{S} / \mathrm{A}=$ the ratio of SH/AH. It should be noted that the measuring unit has been converted to $\mathrm{mg} / \mathrm{g}$ clay-sized fraction $(\mathrm{CF})$

(Table 3). In addition, the group composition of the free and CM-bound fractions also exhibits significant differences. The nonpolar fraction $(\mathrm{SH}+\mathrm{AH})$ accounts for $75.73 \%-78.46 \%$ and $72.31 \%-90.65 \%$ of the $\mathrm{Es}^{3}$ and $\mathrm{Es}^{4}$ free fractions, respectively. In contrast, the polar fraction $(\mathrm{NH}+$ Asphal) accounts for $64.71 \%-80.95 \%$ and $64.29 \%-73.33 \%$ of the $\mathrm{Es}^{3}$ and $\mathrm{Es}^{4} \mathrm{CM}$-bound fractions, respectively. This result indicates that the free fraction is primarily composed of nonpolar OM such as SHs and AHs, while the CM-bound fraction is mainly composed of polar OM, including NHs and asphaltene. Since the CM-bound fractions were of limited abundance, the biomarkers of this certain occurrence might not reach the analytical level of the GC/MS instrument.

\subsubsection{Molecular characterization of saturated hydrocarbons of the free fractions}

GC/MS analysis of the saturated hydrocarbons of the free fraction could provide its molecular composition and biomarker distribution, which is frequently used to indicate thermal maturity, interpret biogenic origin, and elucidate depositional environments (Volkman 1988; Grantham et al. 1988; Peters et al. 2005; Huang et al. 2016). In our research, sample 1327 and 1312 could represent the typical characteristics of the $\mathrm{Es}^{3}$ and $\mathrm{Es}^{4} \mathrm{CFs}$, respectively, and were carefully analyzed on the molecular level. The ratio of $\mathrm{Pr} / \mathrm{Ph}$ (pristane/phytane) of $\mathrm{Es}^{3} 1327$ and $\mathrm{Es}^{4} 1312$ is 1.29 and 0.56, respectively (Fig. 2a, c), with $\mathrm{Es}^{4}$ displaying strong phytane dominance, indicating reducing depositional conditions. In addition, the detection of $\beta$-carotane at the high molecular ends of the Es ${ }^{4}$ TIC, and the relatively high abundance of gammacerane, tricyclic terpanes, and $\mathrm{C}_{33}-\mathrm{C}_{35}$ homohopane series in the $\mathrm{Es}^{4} \mathrm{~m} / \mathrm{z} 191$ mass chromatograph, also suggest that $\mathrm{Es}^{4}$ was formed in saline lacustrine environments, with persistent water stratification and bottom anoxia. Different from $\mathrm{Es}^{4}$, the $\mathrm{Es}^{3}$ displays typical features of fresh lacustrine environments. As seen in Fig. 2, the $\mathrm{Es}^{3} 1327$ displays a uni-modal $n$-alkane distribution, with $n \mathrm{C}_{16}$ being the maximum, and shows distinct odd-even predominance in the $n \mathrm{C}_{23}-n \mathrm{C}_{29}$ range, indicative of terrestrial input. As is shown in the $m / z 217$ mass chromatograph, the 4-methyl steranes of $\mathrm{Es}^{3} 1327$ are of relatively high abundance and extensive variety compared to $\mathrm{Es}^{4}$ (Fig. 3). Since 4-methyl steranes are specifically indicative of dinoflagellate input (Pang et al. 2005; Peters et al. 2005), it is concluded that dinoflagellates were a major source for $\mathrm{OM}$ input of the $\mathrm{Es}^{3}$. The relative abundance of $\mathrm{C}_{27}-\mathrm{C}_{29}$ regular steranes could also serve as OM-origin indicators, of which $\mathrm{C}_{27}$ steranes represent $\mathrm{OM}$ input from aquatic organisms, and $\mathrm{C}_{29}$ represent terrestrial input (Peters et al. 2005). It should be pointed out that the $\mathrm{C}_{29}$ steranes could also originate from planktonic green algae (Grantham 1986; Meng et al. 2006), whose body fossils were also found in the Shahejie Formation (Fan et al. 2002), which makes the biogenic interpretation based on $\mathrm{C}_{27} / \mathrm{C}_{29}$ sterane relative abundance more ambiguous. Since $\mathrm{Es}^{3} 1327$ features $\mathrm{C}_{27}$ sterane dominance, whereas $\mathrm{Es}^{4} 1312$ is characterized by $\mathrm{C}_{29}$ sterane dominance (Fig. 3), it could simply be concluded that the $\mathrm{Es}^{3}$ and $\mathrm{Es}^{4}$ samples were sourced from different algae species. Thermal maturity of $\mathrm{Es}^{3}$ and $\mathrm{Es}^{4}$ could be inferred by hopane and sterane parameters listed in Table 4, all of which have reached their balance points, suggesting the $\mathrm{Es}^{3}$ and $\mathrm{Es}^{4}$ samples are in the maturity range of the oil-generation window. It must be noted that the high Ts/Tm value of $\mathrm{Es}^{4}$ (2.05, Table 4) is the consequence of saline environments, thus not capable of maturity indication (Fig. 3).

\subsubsection{Molecular characterization of saturated hydrocarbons of the CM-bound fractions}

GC/MS analyses of the CM-bound fractions of $\mathrm{Es}^{3}$ and $\mathrm{Es}^{4}$ CFs show three interesting findings: (1) The bicyclic 
(a)
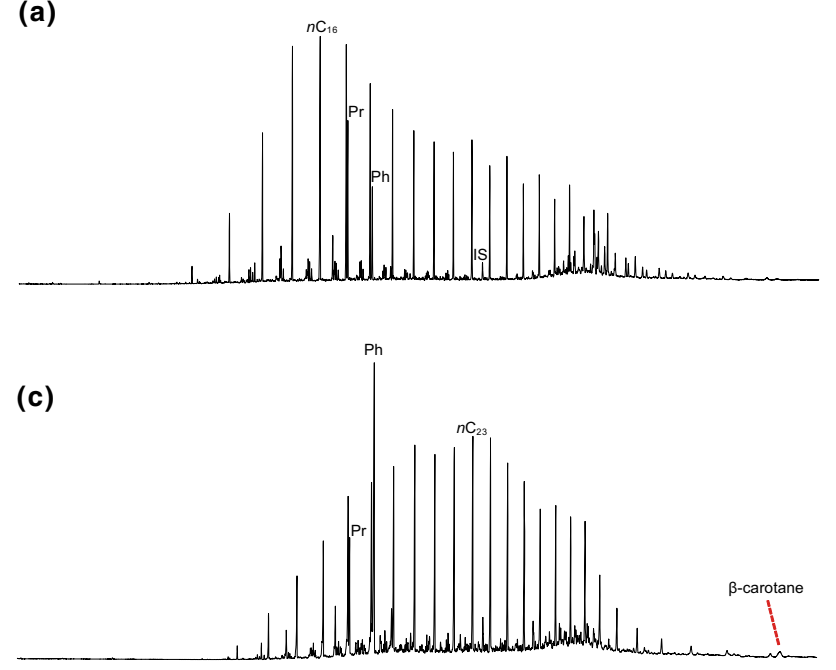

Fig. 2 Total ion chromatograms (TICs) of the free fractions of $\mathrm{Es}^{3}$ 1327 (a) and $\mathrm{Es}^{4} 1312$ (c) CFs, and TICs of the CM-bound fractions of $\mathrm{Es}^{3} 1327$ (b) and $\mathrm{Es}^{4} 1312$ (d) CFs. It is obvious that the BSs are specifically detected with quite high abundance in the CM-bound fractions, and the BSs are highlighted in the TICs of the CM-bound

(a)

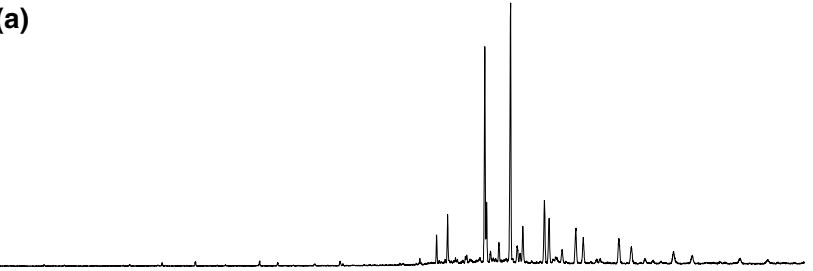

(c)

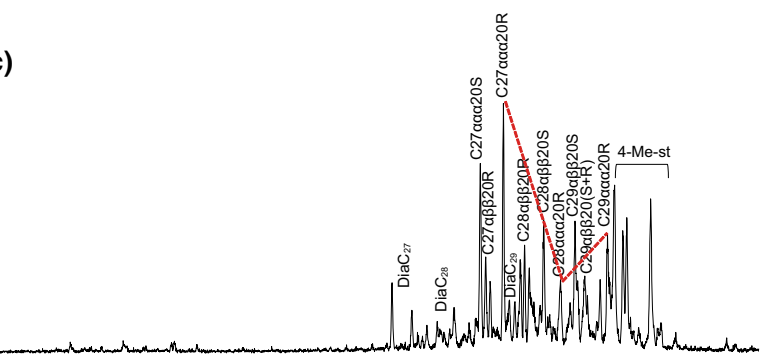

Fig. $3 \mathrm{~m} / z, 191$ mass chromatographs of the free fractions of $\mathrm{Es}^{3} 1327$ (a) and $\mathrm{Es}^{4} 1312$ (b) CFs, and $\mathrm{m} / z 217$ mass chromatographs of the free fractions of $\mathrm{Es}^{3} 1327$ (c) and $\mathrm{Es}^{4} 1312$ (d) CFs. Abbreviations: $C_{x} T T$ tricyclic terpanes, with $x$ indicating the carbon number; $T s$ $18 \alpha(\mathrm{H})-22,29,30$-trinorhopane; $T m$ 17 $\alpha(\mathrm{H})-22,29,30$-trinorhopane;

sesquiterpanes (BSs) are specifically detected with quite high abundance in the CM-bound fractions (Fig. 2b, d). The detailed distribution of BSs is displayed in the $\mathrm{m} / \mathrm{z} 123$ mass chromatograph (Fig. 4). The BS compounds of $\mathrm{Es}^{3}$ CM-fraction are distributed in the $\mathrm{C}_{13}-\mathrm{C}_{16}$ range, whereas $\mathrm{Es}^{4}$ is in the $\mathrm{C}_{13}-\mathrm{C}_{15}$ range, both having $\mathrm{C}_{15}$ as the maximum. In addition, the $\mathrm{C}_{15} \mathrm{BSs}$ of $\mathrm{Es}^{4}$ exhibit more
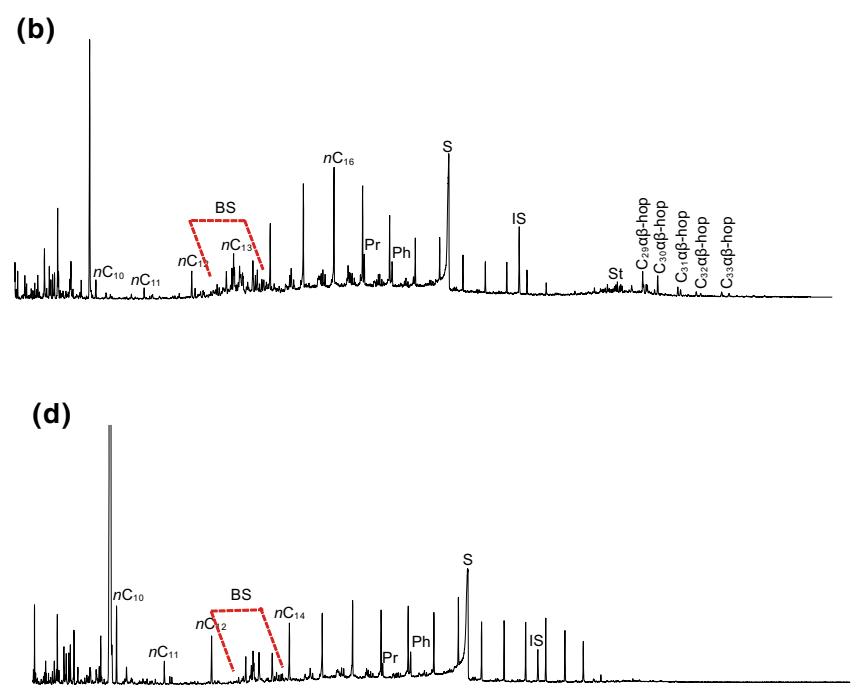

fraction. Abbreviations: $P r$ pristane; $P h$ phytane; $I S$ internal standard, here refers to $n-\mathrm{C}_{24} \mathrm{D}_{50}$; St steranes; $S$ elemental sulfur; $C_{x} \alpha \beta$-hop hopanes of the configuration $17 \alpha, 21 \beta$, with $x$ indicating the carbon number; $B S$ bicyclic sesquiterpenoids; $n C_{x}$ normal alkanes, with $x$ indicating the carbon number

(b)

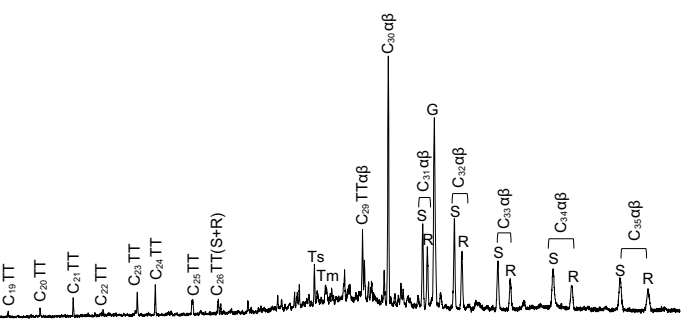

(d)

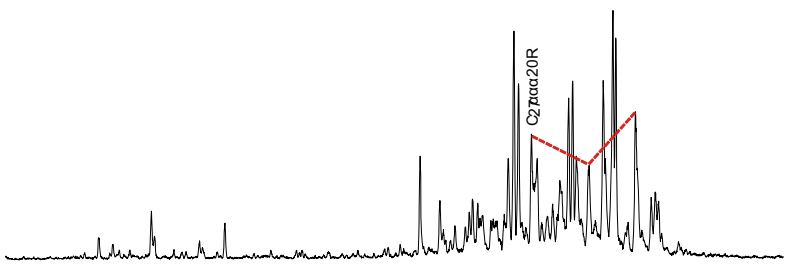

$C_{x} \alpha \beta$ hopanes of the configuration $17 \alpha, 21 \beta$, with $x$ indicating the carbon number; $D_{i a} C_{x}$ diasterane, with $x$ indicating the carbon number; 4-Me-st 4-methyl steranes; $C_{x} \alpha \alpha \alpha 20 R$ sterane with $5 \alpha, 17 \alpha$, $21 \alpha, 20 \mathrm{R}$ configuration, with $x$ indicating the carbon number

extensive isomeric diversity compared to those of $\mathrm{Es}^{3}$. Since the acid hydrolysis had destroyed the bounding interactions between carbonates and associated $\mathrm{OM}$, and the released OM might also have been altered to some extent, it is difficult to determine the specific structure of each labeled peak, but these compounds could still be positively categorized as BSs, as the distinct basic peaks of 
Table 4 Sterane and hopane biomarker series based maturity parameters

\begin{tabular}{lllllll}
\hline Sample number & \multicolumn{2}{l}{ Hopane-based maturity parameters } & & \multicolumn{2}{l}{ Sterane-based maturity parameters } \\
\cline { 2 - 4 } & $\mathrm{Ts} / \mathrm{Tm}$ & $\mathrm{C}_{31} \alpha \beta 22 \mathrm{~S} / 22(\mathrm{~S}+\mathrm{R})$ & $\mathrm{C}_{32} \alpha \beta 22 \mathrm{~S} / 22(\mathrm{~S}+\mathrm{R})$ & & $\mathrm{C}_{29} \beta \beta /(\beta \beta+\alpha \alpha)$ & $\mathrm{C}_{29} \alpha \alpha \alpha 20 \mathrm{~S} / 20(\mathrm{~S}+\mathrm{R})$ \\
\hline 1327 & 0.59 & 0.56 & 0.59 & 0.32 & 0.46 \\
1312 & 2.05 & 0.60 & 0.58 & 0.60 & 0.51 \\
\hline
\end{tabular}
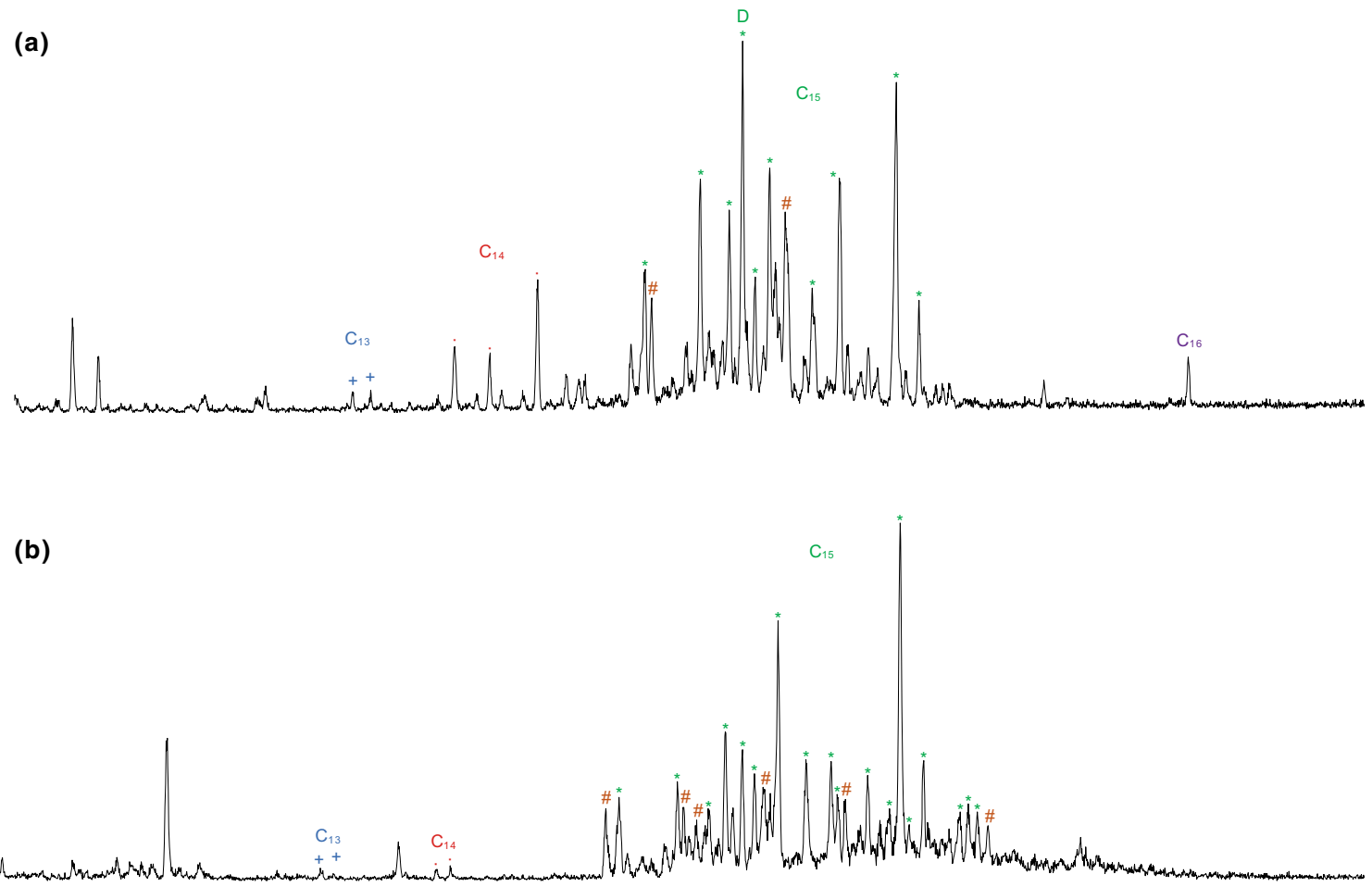

Fig. $4 \mathrm{~m} / \mathrm{z} 123$ mass chromatographs of the CM-bound fractions of $\mathrm{Es}^{3} 1327$ (a) and $\mathrm{Es}^{4} 1312$ (b). $\mathrm{C}_{15}$ BSs were labelled with "*” and "\#", the former featured with basic peak 123, and the latter with 137.

123 and 137 were clearly shown in corresponding mass spectra. The BS biomarkers found in the Dongying Sag could indicate OM input from Botryococcus braunii (Xia and Luo 1994; Wang et al. 1996; He et al. 2004; Ji et al. 2008, 2009). (2) The light ends of the alkanoic hydrocarbons are much better preserved in the CM-bound fraction compared to the free fraction (Fig. 5). The $\mathrm{m} / \mathrm{z}, 85$ mass chromatograph was selected to display the $n$-alkane distribution of the $\mathrm{Es}^{3}$ and $\mathrm{Es}^{4} \mathrm{CM}$-bound fractions, showing that the light ends of CM-bound fraction begin from $n \mathrm{C}_{8}$, whereas the free fraction begins with $n \mathrm{C}_{12}$. A secondary artificial cause for such differences in low-molecularweight OM preservation could definitely be excluded, as the free and CM-bound fractions were subjected to the very same treatment procedure, both were extracted with DCM and had undergone the same group separation treatment as described in 2.5. Besides, the molecular characteristics of
Abbreviations: $C_{x} x$ indicating the carbon number of BSs; BSs of the same carbon number are labeled with the same color; $D$ drimane

each clay-sized sample varied, representing their unique geological conditions. Meanwhile, distinct even-odd predominance could be identified in the $n \mathrm{C}_{15}-n \mathrm{C}_{20}$ range of the $\mathrm{Es}^{4} \mathrm{CM}$-bound fraction, which was a primary molecular feature of Botryococcus braunii (Grice et al. 2003), only having a chance to be observed when hydrocarbons with low molecular weights were well preserved (Silva et al. 2016). (3) Elementary sulfur, of octatomic structure, is detected with quite high abundance in the CM-bound fraction (Fig. 2b, d). Although the saturated hydrocarbons of both the free and CM-bound fractions were not subjected to desulfurization treatments, only the CM-bound fraction was found to contain a significant amount of elemental sulfur, as shown in the TICs of $\mathrm{Es}^{3} 1327$ and Es ${ }^{4}$ 1312 in Fig. 2. Previous study suggests that sulfur content is a significant factor in controlling the occurrence of biomarker isomers (Wang et al. 2010); thus, the selective 


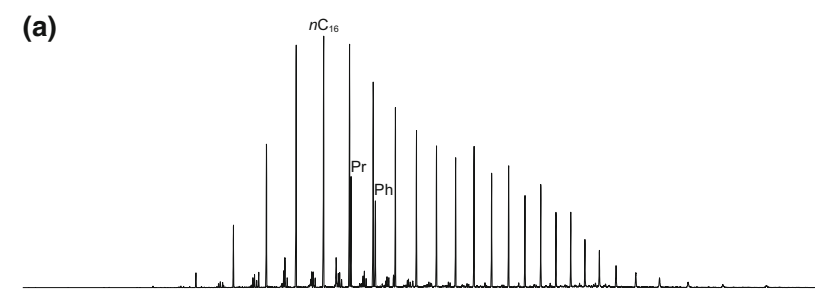

(c)

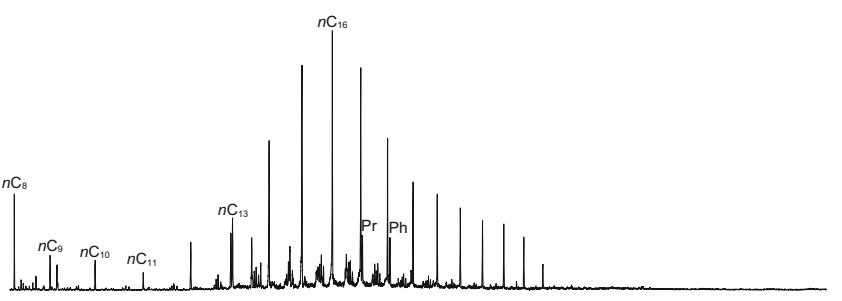

Fig. $5 \mathrm{~m} / \mathrm{z} 85$ mass chromatographs of the free fractions of $\mathrm{Es}^{3} 1327$ (a) and $\mathrm{Es}^{4} 1312$ (b), and $\mathrm{m} / \mathrm{z}, 85$ mass chromatographs of the CMbound fractions of $\mathrm{Es}^{3} 1327$ (c) and $\mathrm{Es}^{4} 1312$ (d). Abbreviations are

detection of sulfur in the CM-bound fraction might reveal distinctions in OM preservation and evolution between these fractions. It should be stated that the proportional distribution of light and heavy hydrocarbons of the CMbound fraction better resembles authentic in situ geological samples than does that of the free fraction: The relatively high temperature and strata pressure underground could help retain the light or gaseous hydrocarbons in source rock pore spaces, which would be easily lost when exposed to surface conditions (Cai et al. 2013). However, the relatively confined environment of carbonate crystals, evidenced by the well preserved elemental sulfur, helped light hydrocarbon preservation during the long time periods.

Based on the aforementioned, it can be concluded that the geochemical information derived from the CM-bound fraction could serve as a supplement to that from the free fraction. Since the CM-bound fraction showed clear advantages in low-molecular-weight OM preservation, it is worthwhile to be analyzed on the molecular level.

\section{Discussion}

\subsection{Biogenic interpretation significance of the CM-bound fraction}

Early incorporation of fatty acids, isoprenoids, sterols, hopanoids, and other biomarker precursors into the macromolecular network of kerogen/asphaltene, or absorbance onto the surface of clay minerals, or entrapped in the crystals of carbonates during early diagenesis are found to be common under geologic conditions (Xie et al. 2000;

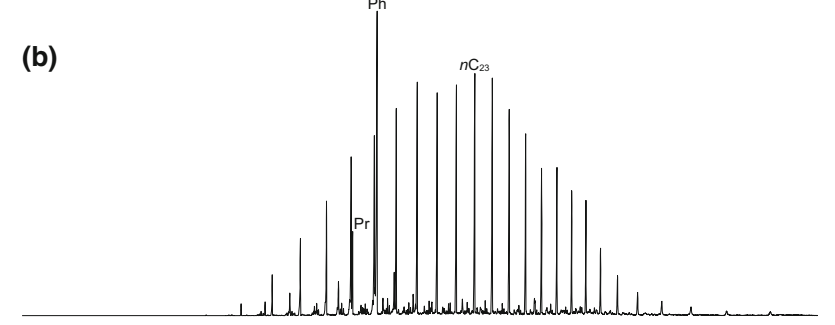

(d)

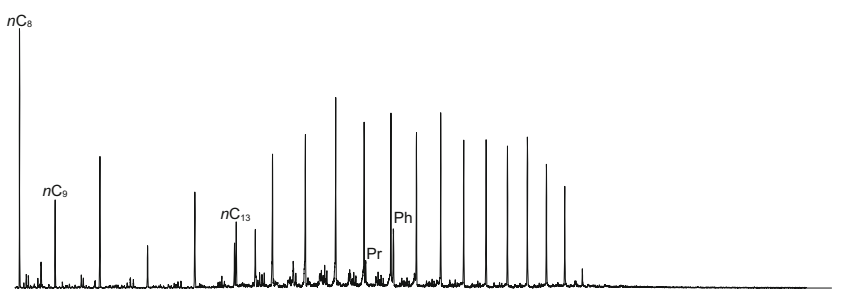

the same as described in Fig. 2. It should be noted that part of the high molecular ends of the CM-bound fractions (c, d) were eluted into the $\mathrm{AH}$ fraction, and the reason responsible for this flaw is yet unclear

Wang and Cheng 2000; Kennedy et al. 2002; Farrimond et al. 2003; Li et al. 2008a, b; Chen and Peng 2017). Because of the steric protection provided by the macromolecular network and inorganic minerals, the bound fraction shows retarded responses to thermal evolution and biodegradation ( $\mathrm{Li}$ et al. 2008a, b; Glombitza et al. 2016; $\mathrm{Wu}$ and Geng 2016). In addition, the free and bound OM fractions exhibit different OM preservation mechanisms, as the bonding interactions between minerals and associated $\mathrm{OM}$ alters the preservation conditions (Zonneveld et al. 2010; Cai et al. 2013; Makeen et al. 2015; Zhu et al. 2016). Thus, it is theoretically reasonable to deduce that the bound $\mathrm{OM}$ fraction has the potential to preserve additional geochemical information on the molecular level, which has already been verified by previous research (e.g. Li et al. 2008a, b; Wu and Geng 2016). Therefore, it is meaningful to analyze the CM-bound fraction on the molecular level to reveal its geochemical significance.

Previous studies on $\mathrm{Es}^{3}$ and $\mathrm{Es}^{4}$ source rocks of the Dongying Sag have suggested that the ancient lake was highly productive, occupied by various algal species that contributed to the OM abundance of these excellent source rocks (Zhang et al. 2009). Body fossils of various algae species could be identified in the $\mathrm{Es}^{3}$ and $\mathrm{Es}^{4}$ source rocks by microscopic analysis, including coccolithophores, dinoflagellates, Botryococcaceaes, Deflandreas, and Bohaidinas (Fan et al. 2002; Zhu and Jin 2003; Ma et al. 2017b). Furthermore, certain algae species could be identified on the molecular level, for instance, dinoflagellates and Botryococcus braunii could be indicated by 4-methyl steranes and BSs, respectively (Pang et al. 2005; Luo and Shen 2005; Ji et al. 2008). Much research suggests that BSs 
are indicative of terrestrial input, especially of angiosperm origin (Peters et al. 2005; Nytoft et al. 2009). However, in the case of the Eocene Shahejie Formation, the BS biomarkers are specifically indicative of Botryococcus braunii origin, which has been verified by previous research, evidenced by the similarity of BS distribution characteristics of source rocks and Botryococcus braunii thermal-degradation products (Xia and Luo 1994; Wang et al. 1996; Salmon et al. 2009; Zhang et al. 2014). In addition, it is ubiquitous for Botryococcus braunii to serve as an important precursor for hydrocarbon generation in the Mesozoic-Cenozoic strata in China; including the Eocene of the Bohai Bay Basin, the Eocene of the Qaidam Basin, the Cretaceous of the Songliao Basin, and the Jurassic of the Tarim, Ordos, and Junggar basins (Summons et al. 2002; He et al. 2004; Luo and Shen 2005; Hofmann et al. 2005; Zhang et al. 2007; Ji et al. 2008, 2009, 2010; Volkman et al. 2015). Refined oil-source correlations suggested that close genetic relationships existed between the giant hydrocarbon reserves and Botryococcus brauniibearing source rocks in the Jiyang Depression (Luo and Shen 2005). In fact, Botryococcus braunii input to the sedimentary OM could be traced back to Precambrian (Volkman 2014), and due to its high hydrocarbon content, Botryococcus braunii is now used as a significant substrate for biofuel production (Audino et al. 2002; Metzger and Largeau 2005). Thus, it could be concluded that Botryococcus braunii is of great hydrocarbon potential, and could be identified by its unique biomarkers, the BSs, in the Mesozoic-Cenozoic strata in China.

The BSs detected in the CM-bound fractions of the $\mathrm{Es}^{3}$ and $\mathrm{Es}^{4} \mathrm{CFs}$ are listed in the $\mathrm{m} / \mathrm{z}, 123$ mass chromatographs in Fig. 4. There are two possible explanations why these biomarkers could not be detected in the free fractions. First, the BSs are of relatively low molecular weight compared to the hopanoid and steroid biomarkers, and as a result the BSs in the free OM fractions were easily lost during the time-consuming preparation period, and the heating treatment would accelerate their diffusion as well. However, thanks to the protection provided by carbonate crystals, the BS compounds in the CM-bound fractions are well preserved, as evidenced by the better preservation of light hydrocarbons, which started from $n \mathrm{C}_{8}$ (Fig. 5). Second, the BS biomarkers might be selectively preserved in the CMbound fractions, or selectively released by acid hydrolysis treatment. The former is more feasible as there exists persuasive molecular evidence. Thus, the CM-bound fractions do have biogenic significance, which could serve as a supplement to the biogenic interpretation based on the free $\mathrm{OM}$ fraction.

\subsection{Possible explanations for the compositional differences between the free and CM-bound fractions}

The free and CM-bound fractions show markedly different group compositions, with the free fractions dominated by non-polar hydrocarbons, and the CM-bound fractions dominated by NHs and asphaltene (Table 3 ), which could be ascribed to their differences in thermal evolution, and thereafter hydrocarbon generation and expulsion. In addition, their differences in OM biogenic origin might exhibit influences on their compositional differences as well, which will be discussed in details afterwards.

First, the free and CM-bound fractions underwent differential thermal evolution with the increase of burial depth of the $\mathrm{Es}^{3}$ and $\mathrm{Es}^{4}$ source rocks. Because of the steric protection provided by carbonate crystals, the CM-bound fractions showed relatively lower maturity compared to their free counterparts. However, due to the limited amount of the SHs of the CM-bound occurrence, biomarker-based maturity parameters could not be accurately calculated, thus direct maturity comparisons between the free and CMbound fractions could not be achieved. As it is widely accepted that the thermal evolution of OM could be expressed as "kerogen-asphaltene/nonhydrocarbon-free hydrocarbons" (Tissot and Welte 1984; Tissot et al. 1987), the free fractions with relatively higher maturity should have a higher compositional percentage of non-polar hydrocarbons than that of the CM-bound fractions, which is consistent with our results, demonstrating the CM-bound fractions were of lower thermal maturity. Second, hydrocarbon products of the free and CM-bound fractions have undergone differential expulsion due to their differences in pore connectivity to adjacent sandstone carriers. It is obvious that the free fractions were better communicated with adjacent sandstone carriers, whereas the CM-bound fractions were confined in relatively closed environments, evidenced by the detection of elemental sulfur (Fig. 2). The polar nonhydrocarbons and asphaltene migrated less easily compared to the non-polar hydrocarbons (Chen et al. 2011), and as a result, the free fractions with higher thermal maturity and better expulsion conditions show much higher content of saturated and aromatic hydrocarbons, whereas the CM-bound fractions with lower maturity and worse expulsion conditions are dominated by nonhydrocarbons and asphaltene. Third, the free and CM-bound fractions are of subtly different biogenic origin based on biomarker analysis. 4-methyl steranes indicative of dinoflagellate input were only detected in the free fractions, whereas the BSs indicating Botryococcus braunii origin were specifically detected in the CM-bound fractions. Since different algal species have their unique intrinsic nature, their 
thermal evolution and hydrocarbon generation patterns would exhibit influences on the thermal products, which would in the end be expressed in the group compositions of the free and CM-bound fractions.

\subsection{Environmental influences on the geochemistry of free and CM-bound fractions}

Molecular characterization of the free fractions suggested that the $\mathrm{Es}^{3}$ and $\mathrm{Es}^{4}$ source rocks were developed in markedly different depositional environments, with $\mathrm{Es}^{3}$ and $\mathrm{Es}^{4}$ formed in fresh and saline lacustrine environments respectively (Fig. 2a, c). Previous research indicated that mineralogical composition, mainly the relative abundance of illite and smectite, could influence OM preservation and hydrocarbon expulsion of source rocks (Li et al. 2017b). As the $\mathrm{Es}^{3}$ and $\mathrm{Es}^{4} \mathrm{CFs}$ differ in clay mineral composition as influenced by depositional environment and burial depth, with $\mathrm{Es}^{4}$ dominated by illite layers (Table 2), hydrocarbon expulsion of $\mathrm{Es}^{4}$ was therefore enhanced, which could be verified by the relatively lower Rock-Eval pyrolysis $S_{2}$ of the $\mathrm{Es}^{4} \mathrm{CFs}$ compared to those of $\mathrm{Es}^{3}$ (Table 1). On the whole, the geochemical interpretation based on the CMbound fractions was consistent with their free counterparts, and distinct molecular differences existed between the CMbound fractions of the fresh $\mathrm{Es}^{3}$ and saline $\mathrm{Es}^{4} \mathrm{CFs}$, mainly reflected in the distribution patterns of $n$-alkanes $(\mathrm{m} / z, 85$ mass chromatograph in Fig. 5c, d) and BSs $(\mathrm{m} / \mathrm{z} 123$ mass chromatograph in Fig. 4). Thus, it could be concluded that the molecular differences of the CM-bound fractions between the $\mathrm{Es}^{3}$ and $\mathrm{Es}^{4} \mathrm{CFs}$ could be ascribed to the same reason responsible for the distinction between their free counterparts, which is the differences in developed algal species as a consequence of adaptation to different sedimentary environments (Pang et al. 2005; Zhang et al. 2009; Li et al. 2017a), as evidenced by the source-related biomarkers identified in the free and CM-bound fractions of the $\mathrm{Es}^{3}$ and $\mathrm{Es}^{4} \mathrm{CFs}$. Although Botryococcus braunii, indicated by the BSs in the CM-bound fractions, could thrive in both fresh and saline lacustrine environments, recent research found out that Botryococcus species developed in aquatic environments with medium salinity exhibit better hydrocarbon generation potential (Grice et al. 1998; Furuhashi et al. 2016), which is consistent with our research results and the exploration practice, that compared to the $\mathrm{Es}^{3}$ source rocks, the $\mathrm{Es}^{4}$ was a more significant contributor to the hydrocarbon production of the Dongying Sag.

\section{Conclusions}

(1) We effectively explored the geochemical features of the free and CM-bound fractions of $\mathrm{Es}^{3}$ and $\mathrm{Es}^{4} \mathrm{CFs}$ from the Dongying $\mathrm{Sag}$ in North China. The molecular analyses of the CM-bound fractions demonstrate that they could serve to supplement the geochemical information derived from the free fractions concerning biogenic interpretation, as the BSs, indicative of Botryococcus braunii input in the Dongying Sag, were selectively detected in the CMbound fractions.

(2) The distinctions in the depositional environments of the $\mathrm{Es}^{3}$ and $\mathrm{Es}^{4}$ source rocks were also reflected in the molecular differences of the CM-bound fractions, mainly the differences in $n$-alkanes and BSs distribution patterns. The geochemical interpretation based on the CM-bound fractions was consistent with their free counterparts. Thus, it could be concluded that the differences in developed algal species as a consequence of adaptation to different sedimentary environments, as evidenced by the source-related biomarkers, is the major cause for the geochemical distinctions between the $\mathrm{Es}^{3}$ and Es ${ }^{4} \mathrm{CFs}$.

(3) The free and CM-bound fractions differ significantly in $\mathrm{OM}$ abundance and group composition, with the free fractions as the majority and dominated by saturated hydrocarbons. Differential thermal evolution and, thereafter, the difference in hydrocarbon generation and expulsion of the free and CM-bound fractions, as well as the distinction in biogenic origin reflected by the source-indicated biomarkers, could explain the compositional differences between the $\mathrm{Es}^{3}$ and $\mathrm{Es}^{4} \mathrm{CFs}$.

Acknowledgements This research is funded by NSFC (National Science Foundation of China) No. 41372130.

Open Access This article is distributed under the terms of the Creative Commons Attribution 4.0 International License (http://creative commons.org/licenses/by/4.0/), which permits unrestricted use, distribution, and reproduction in any medium, provided you give appropriate credit to the original author(s) and the source, provide a link to the Creative Commons license, and indicate if changes were made.

\section{References}

Audino M, Grice K, Alexander R, et al. Macrocyclic alkanes in crude oils from the algaenan of Botryococcus braunii. Org Geochem. 2002;33:979-84. https://doi.org/10.1016/s0146-6380(02)00061-x. 
Behar F, Beaumont V, Tenteado HL, et al. Rock-Eval 6 technology: performances and developments. Oil Gas Sci Technol. 2001;56(2):113-34. https://doi.org/10.2516/ogst:2001013.

Cai JG, Song MS, Lu LF, et al. Organo-clay complexes in source rocks - a natural material for hydrocarbon generation. Mar Geol Quat Geol. 2013;33(3):123-31. https://doi.org/10.3724/SP.J. 1140.2013.030123 (in Chinese).

Chen J, Peng PA. A comparative study of free and bound bitumens from different mature source rocks with type III kerogens. Org Geochem. 2017;112:1-15. https://doi.org/10.1016/j.orggeochem. 2017.06.014.

Chen ZH, Zha M, Jin Q, et al. Distribution of sterane maturity parameters in a lacustrine basin and their control factors: a case study from the Dongying Sag, East China. Pet Sci. 2011;8(3):290-301. https://doi.org/10.1007/s12182-011-0146-9.

Fan YF, Gu Q, Huang JF, et al. Geological events recorded in algal fossils of Shahejie Formation, Dongpu Depression, North China. Acta Micropalaeontologica Sinica. 2002;19(3):316-21. https:// doi.org/10.3969/j.issn.1000-0674.2002.03.010 (in Chinese).

Farrimond P, Love GD, Bishop AN, et al. Evidence for the rapid incorporation of hopanoids into kerogen. Geochim Cosmochim Acta. 2003;67(7):1383-94. https://doi.org/10.1016/S00167037(02)01287-5.

French KL, Hallmann C, Hope JM, et al. Reappraisal of hydrocarbon biomarkers in Archean rocks. PNAS. 2015;112(19):5915-20. https://doi.org/10.1073/pnas.1419563112.

Furuhashi K, Hasegawa F, Saga K, et al. Effects of culture medium salinity on the hydrocarbon extractability, growth and morphology of Botryococcus braunii. Biomass Bioenerg. 2016;91:83-90. https://doi.org/10.1016/j.biombioe.2016.05.007.

Glombitza C, Mangelsdorf K, Horsfield B. Differences in bitumen and kerogen-bound fatty acid fractions during diagenesis and early catagenesis in a maturity series of New Zealand coals. Int $\mathbf{J}$ Coal Geol. 2016;153(1):28-36. https://doi.org/10.1016/j.coal. 2015.11.009.

Grantham PJ. The occurrence of unusual $\mathrm{C}_{27}$ and $\mathrm{C}_{29}$ sterane predominance in two types of Oman crude oil. Org Geochem. 1986;9(1):1-10. https://doi.org/10.1016/0146-6380(86)90077-x.

Grantham PJ, Lijmback GWM, Posthuma J. Origin of crude oils in Oman. J Pet Geol. 1988;11(1):61-88. https://doi.org/10.1306/ bf9ab68a-0eb6-11d7-8643000102c1865d.

Grice K, Schouten S, Nissenbaum A, et al. A remarkable paradox: sulfurised freshwater algal (Botryococcus braunii) lipids in an ancient hypersaline euxinic ecosystem. Org Geochem. 1998; 28(3/4):195-216. https://doi.org/10.1016/s0146-6380(97)00127-7.

Grice K, Schouten S, Blokker P, et al. Structural and isotopic analysis of kerogens in sediments rich in free sulfurized Botryococcus braunii biomarkers. Org Geochem. 2003;34:471-82. https://doi. org/10.1016/s0146-6380(02)00187-0.

Guan P, Xu YC, Liu WH. Different occurrences of organic matters and its quantitative estimation in argillaceous source rocks. Chin Sci Bull. 1998;43(14):1556-9. https://doi.org/10.3321/j.issn: 0023-074X.1998.14.026 (in Chinese)

Guo XW, He S, Liu KY, et al. Modelling the petroleum generation and migration of the third member of the Shahejie Formation (Es3) in the Banqiao Depression of Bohai Bay Basin, Eastern China. J Asian Earth Sci. 2011;40(1):287-302. https://doi.org/ 10.1016/j.jseaes.2010.07.002.

Guo J, Zeng JH, Song GQ, et al. Characteristics and origin of carbonate cements of Shahejie Formation of central uplift belt in Dongying Depression. Earth Sci J China Univ Geosci. 2014;39(5):565-76. https://doi.org/10.3799/dqkx.2014.054 (in Chinese).

He ZJ, Jia FH, Jiang GX, et al. Discovery and Significance of Botryococcus in Duwa Area of Hetian, Xinjiang. Xinjiang Pet
Geol. 2004;25(4):400-2. https://doi.org/10.3969/j.issn.10013873.2004.04.016 (in Chinese).

Hofmann P, Duckensell M, Chpitsglous A, et al. Geochemical and organic petrological characterization of the organic matter of lacustrine Eocene oil shales (Prinz von Hessen, Germany): reconstruction of the depositional environment. J Paleolimnol. 2005;33:155-68. https://doi.org/10.1007/s10933-004-4000-6.

Huang HP, Zhang SC, Su J. Palaeozoic oil-source correlation in the Tarim Basin, NW China: a review. Org Geochem. 2016;94:32-46. https://doi.org/10.1016/j.orggeochem.2016.01. 008.

Ji LM, Song ZG, Li JF. Characteristic of biomarkers originating from Botryococcus in the Triassic lacustrine hydrocarbon source rocks and crude oils in the Ordos Basin. Acta Micropalaeontologica Sinica. 2008;25(3):281-90. https://doi.org/10.3969/j.issn.10000674.2008.03.007 (in Chinese).

Ji LM, Li JF, Song ZG. Petroleum geological significance of Botryococcus in Triassic Yanchang Formation, Ordos Basin. Pet Explor Dev. 2009;36(2):156-65. https://doi.org/10.3321/j. issn:1000-0747.2009.02.004 (in Chinese).

Ji LM, Yan K, Meng FW, et al. The oleaginous Botryococcus from the Triassic Yanchang Formation in Ordos Basin, Northwestern China: morphology and its paleoenvironmental significance. J Asian Earth Sci. 2010;38(5):175-85. https://doi.org/10.1016/j. jseaes.2009.12.010.

Kennedy MJ, Pevear DR, Hill RJ. Mineral surface control of organic carbon in black shale. Science. 2002;295(5555):657-60. https:// doi.org/10.1126/science.1066611.

Lafargue E, Marquis F, Pillot D. Rock-Eval 6 applications in hydrocarbon exploration, production and soil contamination studies. Oil Gas Sci Technol. 1998;53(4):421-37. https://doi.org/ 10.2516/ogst: 1998036 .

Li C, Peng PA, Sheng GY, et al. A study of a 1.2 Ga kerogen using $\mathrm{Ru}$ ion-catalyzed oxidation and pyrolysis-gas chromatographymass spectrometry: structural features and possible source. Org Geochem. 2004;35(5):531-41. https://doi.org/10.1016/j.orggeo chem.2004.01.014.

Li SM, Liu KY, Pang XQ, et al. Quantitative prediction of mixedsource crude oils and its significance for understanding oil accumulation in subtle pools in the Dongying Depression, Bohai Bay Basin. Pet Sci. 2008a;5(3):203-11. https://doi.org/10.1007/ s12182-008-0032-2.

Li YX, Geng AS, Liu JP, et al. Organic geochemical characteristics of the lower Palaeozoic carbonate rocks in the Huanghua Depression, Bohai Bay Basin. Pet Geol Exp. 2008b;30(1):75-81. https://doi.org/10.3969/j.issn.1001-6112.2008.01.015 (in Chinese).

Li XL, Hu CY, Huang JH, et al. A 9000-year carbon isotopic record of acid-soluble organic matter in a stalagmite from Heshang Cave, central China: paleoclimate implications. Chem Geol. 2014;388(21):71-7. https://doi.org/10.1016/j.chemgeo.2014.08. 029.

Li TW, Jiang ZX, Li Z, et al. Continental shale pore structure characteristics and their controlling factors: a case study from the lower third member of the Shahejie Formation, Zhanhua Sag, Eastern China. J Nat Gas Sci Eng. 2017a;45:670-92. https://doi. org/10.1016/j.jngse.2017.06.005.

Li YL, Cai JG, Wang XJ, et al. Smectite-illitization difference of source rocks developed in saline and lacustrine water environments and its influence on hydrocarbon generation: a study from the Shahejie Formation, Dongying Depression, China. Mar Pet Geol. 2017b;80:349-57. https://doi.org/10.1016/j.marpetgeo. 2016.12.004.

Luo J, Shen Z. Significance of oil shale in the Eocene petroleum resource evaluation of the Jiyang Depression, Bohai Bay Basin. 
Pet Geol Exp. 2005;27(2):164-8. https://doi.org/10.3969/j.issn. 1001-6112.2005.02.012 (in Chinese).

Ma AL, Zhang SC, Zhang DJ. Ruthenium-ion-catalyzed oxidation of asphaltenes of heavy oils in Lunnan and Tahe oilfields in Tarim Basin, NW China. Org Geochem. 2008;39(11):1502-11. https:// doi.org/10.1016/j.orggeochem.2008.07.016.

Ma YQ, Fan MJ, Lu YC, et al. Climate-driven paleolimnological change controls lacustrine mudstone depositional process and organic matter accumulation: constraints from lithofacies and geochemical studies in the Zhanhua Depression, eastern China. Int J Coal Geol. 2016;167(1):103-18. https://doi.org/10.1016/j. coal.2016.09.014.

Ma CF, Derek E, Dong CM, et al. Controls of hydrocarbon generation on the development of expulsion fractures in organic-rich shale: based on the Paleogene Shahejie Formation in the Jiyang Depression, Bohai Bay Basin, East China. Mar Pet Geol. 2017a;86:1406-16. https://doi.org/10.1016/j.marpetgeo.2017. 07035.

Ma YQ, Fan MJ, Lu YC, et al. Middle Eocene paleohydrology of the Dongying Depression in eastern China from sedimentological and geochemical signatures of lacustrine mudstone. Palaeogeogr Palaeoclimatol Palaeoecol. 2017b;479(1):16-33. https://doi.org/ 10.1016/j.palaeo.2017.04.011.

Makeen YM, Hakimi MH, Abdullah WH. The origin, type and preservation of organic matter of the Barremian-Aptian organicrich shales in the Muglad Basin, Southern Sudan, and their relation to paleoenvironmental and paleoclimate conditions. Mar Pet Geol. 2015;65:187-97. https://doi.org/10.1016/j.marpetgeo. 2015.03.003.

Meng FW, Zhou CM, Yan X, et al. Biological origin of early Palaeozoic and Precambrian hydrocarbon source rocks based on C27/C29 sterane ratio and organic carbon isotope. Acta Micropalaeontologica Sinica. 2006;23(1):51-6. https://doi.org/ 10.3969/j.issn.1000-0674.2006.01.006 (in Chinese).

Metzger P, Largeau C. Botryococcus braunii: a rich source for hydrocarbons and related ether lipids. Appl Microbiol Biotechnol. 2005;66:486-96. https://doi.org/10.1007/s00253-004-1779$\mathrm{z}$.

Nytoft HP, Samuel OJ, Kildahl-Andersen G, et al. Novel C15 sesquiterpanes in Niger Delta oils: structural identification and potential applications as new markers of angiosperm input in light oils. Org Geochem. 2009;40(5):595-603. https://doi.org/10. 1016/j.orggeochem.2009.02.003.

Pan YH, Liao YH, Sun YG. The characteristics of bound biomarkers released from asphaltenes in a sequence of naturally biodegraded oils. Org Geochem. 2017;111:56-66. https://doi.org/10.1016/j. orggeochem.2017.06.007.

Pang XQ, Li MW, Li SM, et al. Geochemistry of petroleum systems in the Niuzhuang South Slope of Bohai Bay Basin: part 3. Estimating hydrocarbon expulsion from the Shahejie Formation. Org Geochem. 2005;36(4):497-510. https://doi.org/10.1016/j. orggeochem.2004.12.001.

Peters KE, Walters CC, Moldowan JM. The biomarker guide (Second Edition): Volume 2-Biomarkers and isotopes in petroleum exploration and earth history. Cambridge: Cambridge University Press; 2005. p. 483-602.

Salmon E, Behar F, Lorant F, et al. Thermal decomposition processes in algaenan of Botryococcus braunii race L. Part 1: experimental data and structural evolution. Org Geochem. 2009;40:400-15. https://doi.org/10.1016/j.orggeochem.2008.11.007.

Silva TF, Filho JGM, Silva MC, et al. Botryococcus braunii versus Gloecapsomorpha prisca: chemical composition correlation using laser micropyrolysis-gas chromatography/mass spectrometer (LmPy-GCMSMS). Int J Coal Geol. 2016;168:71-9. https:// doi.org/10.1016/j.coal.2016.08.010.
Snowdon LR, Volkman JK, Zhang ZR, et al. The organic geochemistry of asphaltenes and occluded biomarkers. Org Geochem. 2016;91:3-15. https://doi.org/10.1016/j.orggeochem.2015.11. 005.

Summons RE, Metzger P, Largeau C, et al. Polymethylsqualanes from Botryococcus braunii in lacustrine sediments and crude oils. Org Geochem. 2002;33:99-109. https://doi.org/10.1016/ s0146-6380(01)00147-4.

Tissot BP, Welte DH. Petroleum formation and occurrence. New York: Springer; 1984. p. 23-36.

Tissot BP, Pelet R, Ungerer Ph. Thermal history of sedimentary basins, maturation indices, and kinetics of oil and gas generation. AAPG Bull. 1987;71:1445-66. https://doi.org/10.1306/ 703c80e7-1707-11d7-8645000102c1865d.

Volkman JK. Biological marker compounds as indicators of the depositional environments of petroleum source rocks. Geol Soc Lond Spec Publ. 1988;40(1):103-22. https://doi.org/10.1144/gsl. sp.1988.040.01.10.

Volkman JK. Acyclic isoprenoid biomarkers and evolution of biosynthetic pathways in green microalgae of the genus Botryococcus. Org Geochem. 2014;75:36-47. https://doi.org/10.1016/ j.orggeochem.2014.06.005.

Volkman JK, Zhang ZR, Xie XM, et al. Biomarker evidence for Botryococcus and a methane cycle in the Eocene Huadian oil shale, NE China. Org Geochem. 2015;78:121-34. https://doi.org/ 10.1016/j.orggeochem.2014.11.002.

Wang ZY, Cheng KM. The organic geochemical characteristics comparison and contributors of different existing state organic matter in carbonate rocks. Acta Sedimentol Sin. 2000;18(4):600-5. https://doi.org/10.14027/j.cnki.cjxb.2000.04. 021 (in Chinese).

Wang XH, Zhao L, Song YT. Gas chromatography-mass spectrometry analyses of hydrocarbons produced by different strains of Botryococcus Braunii. Acta Microbiologica Sinica. 1996;36(4):284-91. https://doi.org/10.13343/j.cnki.wsxb.1996. 04.007 (in Chinese).

Wang G, Wang T-G, Simoneit BRT, et al. Sulfur rich petroleum derived from lacustrine carbonate source rocks in Bohai Bay Basin, East China. Org Geochem. 2010;41(4):340-54. https:// doi.org/10.1016/j.orggeochem.2009.12.010.

Warren J, Ziegler SE. A solid phase extraction method for isolating HF-extractable soil organic matter for NMR analysis. Org Geochem. 2017;111:1-8. https://doi.org/10.1016/j.orggeochem. 2017.04.012.

Wu LL, Geng AS. Differences in the thermal evolution of hopanes and steranes in free and bound fractions. Org Geochem. 2016;101:38-48. https://doi.org/10.1016/j.orggeochem.2016.08. 009.

Xia YQ, Luo BJ. The study on formation and evolution of bicyclic sesquiterpane by means of pyrolysis. Acta Sedimentol Sin. 1994;12(3):106-13. https://doi.org/10.14027/j.cnki.cjxb.1994. 03.013 (in Chinese).

Xie QL, Zhou ZY, Lu MY. Organic matter enclosed in carbonate minerals - a kind of important hydrocarbon-producing matter. Acta Mineralogica Sinica. 2000;20(1):59-62. https://doi.org/10. 16461/j.cnki.1000-4734.2000.01.011 (in Chinese).

Zegouagh Y, Derenne S, Largeau C, et al. A geochemical investigation of carboxylic acids released via sequential treatments of two surficial sediments from the Changjiang delta and East China Sea. Org Geochem. 2000;31:375-88. https://doi.org/10. 1016/s0146-6380(00)00007-3.

Zhang ZH, Metzger P, Sachs JP. Biomarker evidence for the cooccurrence of three races (A, B and L) of Botryococcus braunii in El Junco Lake, Galapagos. Org Geochem. 2007;38:1459-78. https://doi.org/10.1016/j.orggeochem.2007.05.015. 
Zhang LY, Liu Q, Zhu RF, et al. Source rocks in Mesozoic-Cenozoic continental rift basins, east China: a case from Dongying Depression, Bohai Bay Basin. Org Geochem. 2009;40(2): 229-42. https://doi.org/10.1016/j.orggeochem.2008.10.013.

Zhang ZR, Volkman JK, Greenwood PF, et al. Flash pyrolysis of kerogens from algal rich oil shales from the Eocene Huadian Formation, NE China. Org Geochem. 2014;76:167-72. https:// doi.org/10.1016/j.orggeochem.2014.08.004.

Zhu GY, Jin Q. Geochemical characteristics of two sets of excellent source rocks in Dongying depression. Acta Sedimentol Sin.
2003;21(3):506-12. https://doi.org/10.3969/j.issn.1000-0550. 2003.03 .022 (in Chinese).

Zhu XJ, Cai JG, Liu WX, et al. Occurrence of stable and mobile organic matter in the clay-sized fraction of shale: significance for petroleum geology and carbon cycle. Int $\mathrm{J}$ Coal Geol. 2016;160(15):1-10. https://doi.org/10.1016/j.coal.2016.03.011.

Zonneveld KAF, Versteegh GJM, Kasten S, et al. Selective preservation of organic matter in marine environments; processes and impact on the sedimentary record. Biogeosciences. 2010;7(2): 483-511. https://doi.org/10.5194/bg-7-483-2010. 